\title{
CARACTERIZAÇÃo QUÍMICA E AVALIAÇÃo DA CITOTOXICIDADE DE UM HETEROPOLISSACARÍDEO ISOLADO DA BIOMASSA DO Colletotrichum gloeosporioides
}

Samara M. A. Alexandre ${ }^{a}$, Maria de Lourdes Corradi da Silva ${ }^{a, *}$, , Ana F. D. Vasconcelos ${ }^{a}$, Dalita G. S. M. Cavalcante ${ }^{\mathrm{b}}$, Aldo E. Job ${ }^{b}$, Luciana G. Ferreira ${ }^{c}$, Miguel D. Noseda ${ }^{c}$ e Maria E. R. Duarte ${ }^{c}$

aDepartamento de Química e Bioquímica, Faculdade de Ciências e Tecnologia, Universidade Estadual Paulista, 19060-900 Presidente Prudente - SP, Brasil

${ }^{\text {b}}$ Departamento de Física, Faculdade de Ciências e Tecnologia, Universidade Estadual Paulista, 19060-080 Presidente Prudente - SP, Brasil

'Departamento de Bioquímica e Biologia Molecular, Centro Politécnico, Universidade Federal do Paraná, 81531-980 Curitiba PR, Brasil

Recebido em 28/08/2018; aceito em 30/01/2019; publicado na web em 13/03/2019

\begin{abstract}
CHEMICAL CHARACTERIZATION AND CYTOTOXIC ACTIVITY OF THE HETEROPOLYSACHARIDE FROM Colletotrichum gloeosporioides BIOMASS. Colletotrichum gloeosporioides biomass was submitted to ethanolic extraction $\left(78^{\circ} \mathrm{C}, 12 \mathrm{~h}\right)$ to remove low molecular weight compounds followed by hot aqueous extraction $\left(100{ }^{\circ} \mathrm{C}, 4 \mathrm{~h}, 4 \mathrm{x}\right)$ to obtain polysaccharides. Consecutive freezing/thawing treatments of the aqueous extract yielded a soluble fraction in cold water that was separated on five components $\left(\mathrm{P}_{\mathrm{I}}\right.$ to $\mathrm{P}_{\mathrm{V}}$ ) by gel exclusion chromatography on Sepharose CL-6B. The $\mathrm{P}_{\mathrm{IV}}$ was homogeneous on HPSEC/RID, with apparent $\mathrm{M}_{\mathrm{W}}$ of $2.8 \times 10^{4} \mathrm{~g} \mathrm{~mol}^{-1}$, Mw/Mn 1.17, $100 \%$ of total sugar. The $\mathrm{P}_{\mathrm{IV}}$ was composed by galactose (61\%), glucose (34\%) and mannose (5\%). ${ }^{1} \mathrm{H}$ and ${ }^{13} \mathrm{C}$ NMR analysis mono- and two-dimensional, homo- (COSY) and heteronuclear (HSQC and HMBC) showed that $\mathrm{P}_{\mathrm{IV}}$ is a heteropolysacharide with a main chain constituted by $\beta$-D-galactofuranosidic units $(1 \rightarrow 5)$ and $(1 \rightarrow 6)$ linked with some of the $\beta$-D-galactofuranosidic $(1 \rightarrow 6)$ units substituted in $O-3$ by $\alpha$-D-glucopiranosidic residues. Cytotoxic assays (MTT) indicated that the viability of CHO-K1 cells, when exposed to different heteropolysaccharide concentrations, did not show significant differences when compared to the viability of the negative control $(\mathrm{CN})$, in the experimental times of 24 and 48 hours. These results suggest the possibility of new cytotoxic assays in other normal cell lines as well as in tumor cells.
\end{abstract}

Keywords: heteropolysaccharide; HPSEC/RID; HSQC; MTT assay.

\section{INTRODUÇÃO}

Grande parte dos carboidratos identificados na natureza está sob a forma de polissacarídeos, que são polímeros com padrão de massa molar variável entre médio $\left(10^{4} \mathrm{~g} \mathrm{~mol}^{-1}\right)$ a alto $\left(10^{6} \mathrm{~g} \mathrm{~mol}^{-1}\right)$. Essas moléculas, também conhecidas por glicanos, podem se diferenciar quanto à composição das unidades monossacarídicas que se repetem ao longo do polímero, nos tipos de ligações glicosídicas, no tamanho e no grau de ramificação das cadeias. ${ }^{1}$ Polissacarídeos microbianos se destacam por apresentar facilidades na sua obtenção. A possibilidade de cultivos sem a interferência de condições climáticas e o uso de espaço físico relativamente pequeno tornam esses biopolímeros atraentes para aplicação. Pelo controle de parâmetros como $\mathrm{pH}$, temperatura, taxa de aeração, velocidade de agitação, tempo de fermentação e composição do meio de cultivo, os polissacarídeos microbianos acabam apresentando menos heterogeneidade em suas propriedades físico-químicas. ${ }^{2}$

Entre esses micro-organismos destacam-se os fungos por disponibilizarem à indústria uma série de produtos com diferentes valores biotecnológicos..$^{3-6} \mathrm{O}$ grande número de espécies fúngicas encontradas nos biomas contribui para esse fato. Eles podem produzir ácidos orgânicos, enzimas, reguladores do crescimento de plantas, alcaloides, pigmentos, toxinas, antibióticos e polissacarídeos. ${ }^{7,8}$ Essas moléculas podem ser isoladas da biomassa e/ou da mistura de metabólitos secretados pelo fungo.

Nos últimos vinte anos, os polissacarídeos fúngicos têm se tornado alvo de pesquisas por apresentarem diferentes aplicações farmacológicas, como glucanas na inibição da replicação de vírus ${ }^{9}$ e estimuladoras do sistema imunológico, ${ }^{10}$ heteropolissacarídeos de manose e arabinose como antioxidante ${ }^{11} \mathrm{e}$ fucomanogalactanas como anti-inflamatório. ${ }^{12}$

O fungo Colletotrichum gloeosporioides pertence ao grupo dos ascomicetos e atua como patógeno em várias espécies de plantas. ${ }^{13}$ Embora Park e colaboradores ${ }^{14}$ tenham isolado e descrito a propriedade dispersante de um exopolissacarídeo produzido por esse micro-organismo, a maior parte dos estudos referentes ao fungo está relacionada à sua fitopatologia, não havendo na literatura nenhum relato sobre a composição química dos polissacarídeos presentes na biomassa do C. gloeosporioides. Considerando que essas macromoléculas constituem mais de $90 \%$ da parede celular, isolá-las, purificá-las e determinar as suas estruturas químicas poderá contribuir não somente com as pesquisas que visam ao combate do fitopatógeno, mas também auxiliar na descoberta de novos agentes farmacológicos, que possam apresentar ações imunomoduladora, anti-coagulante, anti-inflamatória, entre outras.

\section{PARTE EXPERIMENTAL}

\section{Reagentes}

Os principais reagentes utilizados na pesquisa foram de grau analítico. Na cromatografia de filtração em gel à pressão normal, utilizou-se o gel Sepharose CL-6B (Pharmacia Biotech). Os padrões de dextrana (Leuconostoc mesenteroides) utilizados no HPSEC/RID foram adquiridos da SIGMA. 


\section{Métodos analíticos}

Açúcares totais foram determinados pelo método do fenol-ácido sulfúrico ${ }^{15}$ e a glucose foi utilizada como padrão. As proteínas foram determinadas pelo método de Bradford ${ }^{16}$ e soro albumina bovina foi utilizada como padrão.

\section{Manutenção do micro-organismo}

O fungo Colletotrichum gloeosporioides, isolado da Mimosa pudica, foi cedido pela Prof. Dra. Adriana Knob (UNICENTRO - Guarapuava, PR) e identificado pelo Prof. Dr. André Rodrigues (UNESP - Rio Claro, SP). O fungo foi mantido em meio BDA (batata-dextrose-ágar) inclinado, a $4{ }^{\circ} \mathrm{C}$, com repiques trimestrais.

\section{Cultivo do micro-organismo e isolamento da biomassa fúngica}

O C. gloeosporioides foi cultivado segundo Dominato. ${ }^{17}$ Os cultivos foram interrompidos utilizando um sistema de filtração a vácuo para separação da biomassa, que foi lavada, com água destilada, para remoção do meio de cultivo e dos resíduos metabólicos secretados pelo micro-organismo, garantindo que nenhum açúcar residual, do processo de fermentação, contaminasse o material de estudo. Esse procedimento foi efetuado até que a água de lavagem resultasse negativa para o teste do fenol-ácido sulfúrico. ${ }^{15}$ Após este processo a biomassa foi liofilizada.

\section{Extração dos polissacarídeos}

A biomassa liofilizada (53 $\mathrm{g}$ ) foi macerada e submetida a dois diferentes procedimentos extrativos sequenciais, como mostrado pelo fluxograma abaixo (Figura 1).

\section{Purificação dos polissacarídeos do extrato aquoso}

Fracionamento dos polissacarídeos por tratamentos consecutivos de congelamento e descongelamento

$\mathrm{O}$ extrato aquoso $\left(\mathrm{E}_{\mathrm{H} 2 \mathrm{O}-\mathrm{C}}\right)$ foi congelado e, então, descongelado à temperatura ambiente. Este processo resultou em uma fração solúvel e outra insolúvel, separadas por centrifugação $\left(4^{\circ} \mathrm{C}, 30\right.$ $\min , 4800 \times \mathrm{g}$ ). Na fração insolúvel foi adicionada água destilada e, novamente, ambas as frações solúvel e insolúvel foram congeladas e depois descongeladas à temperatura ambiente. Este processo foi repetido diversas vezes, até que as frações solúveis não apresentassem precipitados durante o descongelamento. As frações aquosas contendo os polissacarídeos solúveis foram precipitadas pela adição de álcool etílico na proporção de 1 volume da fração aquosa para 3 volumes de etanol. O precipitado etanólico, após remoção do álcool e solubilização em água, foi dialisado (em tubos de 12.000 MWCO) contra água corrente por $24 \mathrm{~h}$. Após este período a fração retida no tubo de diálise, denominada $\mathrm{PE}_{\mathrm{H}_{2} \mathrm{O}-\mathrm{C}}$, foi liofilizada e pesada $(2,23 \mathrm{~g})$. Dessa fração, foram retiradas alíquotas para dosagens de açúcar total e proteína, determinação da composição monossacarídica após hidrólise ácida total e verificação do grau de homogeneidade por cromatografia de permeação em gel.

\section{Cromatografia de filtração em gel Sepharose CL-6B}

A fração $\mathrm{PE}_{\mathrm{H} 2 \mathrm{O}-\mathrm{C}}$ foi purificada por cromatografia de filtração em gel à pressão normal. O gel selecionado e as condições da análise foram semelhantes ao trabalho efetuado por Alexandre e colaboradores. $^{18}$

\section{Análise da homogeneidade e da massa molecular aparente por HPSEC/RID}

A homogeneidade dos polissacarídeos foi determinada por cromatografia de permeação em gel em cromatógrafo líquido de alta pressão da marca SHIMADZU, com detector de índice de refração diferencial modelo RID 10A, usando quatro colunas de gel permeação da marca WATERS, com limites de exclusão de $7 \times 10^{6}$, $4 \times 10^{5}, 8 \times 10^{4}$ e $5 \times 10^{3} \mathrm{Da}$, dispostas em série. As condições da análise foram: total de material aplicado $200 \mu \mathrm{g}$ em $200 \mu \mathrm{L}$; fluxo de $0,6 \mathrm{~mL} \mathrm{~min}{ }^{-1}$ a $37{ }^{\circ} \mathrm{C}$; eluente: $\mathrm{NaNO}_{3} 0,1 \mathrm{~mol} \mathrm{~L}{ }^{-1}$ contendo azida sódica $0,03 \%$. A determinação das massas moleculares aparentes foi realizada utilizando-se uma curva de calibração com padrões de dextrana com massas moleculares variando de $9,4 \times 10^{3}$ a $6,3 \times 10^{5} \mathrm{Da}$.

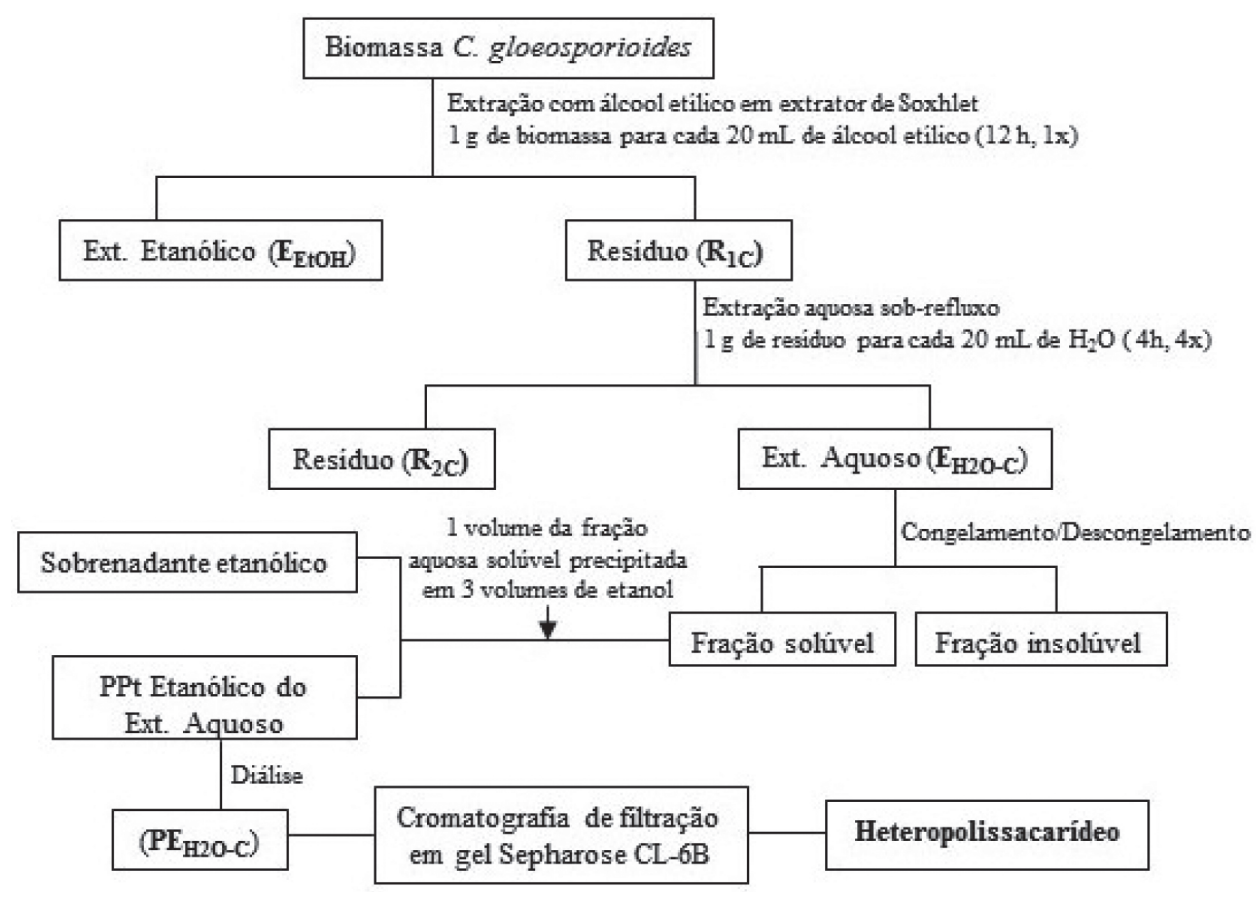

Figura 1. Fluxograma dos procedimentos para obtenção dos polissacarídeos fúngicos 
Análise de monossacarídeos por HPAEC/PAD

Para análise dos monossacarídeos, alíquotas de $50 \mu \mathrm{g}$ de açúcares totais, de cada fração, foram hidrolisadas com TFA 4 mol L ${ }^{-1}$, $100{ }^{\circ} \mathrm{C}$, por $6 \mathrm{~h}$. O ácido foi removido em evaporador rotativo, a baixa pressão, e solubilizado em água deionizada. Frações contendo cerca de $1 \mu \mathrm{g}$ de açúcares totais em $25 \mu \mathrm{L}$ de água deionizada foram injetadas em HPAEC (Dionex DX500) equipado com um detector de amperometria pulsada (PAD). Os açúcares neutros foram separados isocraticamente, usando uma coluna analítica CarboPac PA1 equipada com guarda coluna PA1, ao fluxo de $1 \mathrm{~mL} \mathrm{~min}^{-1}$. As condições de eluição foram produzidas utilizando $\mathrm{H}_{2} \mathrm{O}$ deionizada (eluente 1) e 7\% $\mathrm{NaOH} 200 \mathrm{mmol} \mathrm{L}^{-1}$ (eluente 2), resultando em uma fase móvel de $\mathrm{NaOH} 14 \mathrm{mmol} \mathrm{L}^{-1}$, com corridas de 25 min de duração.

Análise dos espectros de $\mathrm{RMN}$ de ${ }^{1} \mathrm{He}{ }^{13} \mathrm{C}$

Os espectros de $\mathrm{RMN}$ de ${ }^{1} \mathrm{H}$ e ${ }^{13} \mathrm{C}$ foram obtidos em espectrômetro Bruker, modelo Avance-DRX-400. O heteropolissacarídeo foi solubilizado em água deuterada $99 \%$, em tubos de $5 \mathrm{~mm}$ de diâmetro e mantidos a $30{ }^{\circ} \mathrm{C}$ durante a análise. Os deslocamentos químicos foram expressos em $\delta(\mathrm{ppm})$ relativos aos sinais de ${ }^{13} \mathrm{C}$ e ${ }^{1} \mathrm{H}$ da acetona deuterada em $\delta 30,2$ e 2,224, respectivamente. Os experimentos de ressonância magnética nuclear bidimensionais foram realizados usando um software Bruker e incluíram as correlações homonuclear ${ }^{1} \mathrm{H} /{ }^{1} \mathrm{H}(\mathrm{COSY})$ e heteronucleares HSQC (heteronuclear single quantum coherence) e HMBC (heteronuclear multiple bond correlation).

\section{Teste biológico: atividade citotóxica}

A linhagem celular usada neste estudo foi a CHO-K1 (Células de Ovário de Hamster Chinês). As células foram cultivadas em $10 \mathrm{~mL}$ de DMEM/F10 suplementada com $10 \%$ de soro bovino fetal em frascos de $25 \mathrm{~cm}^{2}$ e mantidas em incubadora sem $\mathrm{CO}_{2}$ a $37{ }^{\circ} \mathrm{C}$.

\section{Preparo das amostras para o teste de toxicidade}

Para o teste a fração $\mathrm{P}_{\mathrm{IV}}$ foi diluída em tampão fosfato-salino (PBS) na concentração de $1 \mathrm{mg} \mathrm{mL}^{-1}$ e colocada em agitação constante overnight, em ambiente climatizado a $24 \pm 2{ }^{\circ} \mathrm{C}$. Para melhorar a homogeneidade, a amostra foi submetida ao banho de ultrassom por um período de uma hora e, em seguida, centrifugada (5 min, $5000 \mathrm{rpm}$ ). O sobrenadante foi esterilizado, em fluxo laminar, utilizando filtro de seringa estéril com porosidade de 0,22 $\mu \mathrm{m}$. Para obter a concentração efetiva de açúcar no material que transpôs o filtro, uma alíquota do filtrado foi quantificada pelo método do fenol-ácido sulfúrico. ${ }^{15} \mathrm{~A}$ partir desta informação, diferentes concentrações do $\mathrm{P}_{\mathrm{IV}}$ $\left(25,50,100,200\right.$ e $\left.400 \mu \mathrm{g} \mathrm{mL}^{-1}\right)$ foram preparadas a partir da solução filtrada estéril e usadas para os testes de toxicidade.

\section{Protocolo de exposição e ensaio de citotoxicidade}

O potencial citotóxico das diferentes concentrações foi avaliado pelo método de redução do brometo de 3-(4,5-dimetiltiazol2-yl)-2,5-difeniltetrazólio (MTT), de acordo com Mosmann. ${ }^{19}$ As células foram semeadas numa placa transparente de 96 poços na densidade inicial de 2,0 x $10^{5}$ células por poço. As células foram incubadas com PBS e meio de cultura $(1: 1)$, controle negativo $(\mathrm{CN})$ ou com diferentes concentrações da amostra (25, 50, 100, 200 e $\left.400 \mu \mathrm{g} \mathrm{mL}^{-1}\right)$ e meio de cultura (1:1), pelos tempos experimentais de 24 e $48 \mathrm{~h}$. Um controle positivo (CP) também foi preparado na concentração de $1 \%$ de Triton-X.

Após a finalização dos tempos experimentais (24 e 48 h), o sobrenadante das culturas foi cuidadosamente removido, e então, adicionado em cada poço $200 \mu \mathrm{L}$ do MTT $\left(0,5 \mathrm{mg} \mathrm{mL}^{-1}\right.$ de meio de cultura). As células foram incubadas novamente por mais $4 \mathrm{~h}$. Após esse período, o sobrenadante resultante foi removido e $200 \mu \mathrm{L}$ de
DMSO foram adicionados. A absorbância correspondente foi determinada a $540 \mathrm{~nm}$ em leitor de microplacas. A absorbância obtida para o controle negativo foi considerada como $100 \%$ de viabilidade celular (VC). A VC das outras amostras foi determinada pela seguinte fórmula: $\mathrm{VCE}=[(\mathrm{AE}-\mathrm{AB}) /(\mathrm{ACN}-\mathrm{AB})]$ x 100 onde: $\mathrm{VCE}=$ viabilidade celular das células expostas ao material; $\mathrm{AE}=$ Absorbância encontrada para células expostas ao material; $\mathrm{ACN}=$ Absorbância encontrada para as células do controle negativo; $\mathrm{AB}=$ Absorbância encontrada para o branco (poço apenas com DMSO).

\section{Análises estatísticas}

Os resultados foram comparados por análise paramétrica de variância (ANOVA), utilizando o método Student-Newman-Keuls ou o teste não paramétrico de Kruskal-Wallis, de acordo com a distribuição dos dados (normalidade e homogeneidade de variância). Valores de $\mathrm{p}<0,05$ foram considerados significativos e os resultados foram expressos em média \pm SE (desvio padrão).

\section{RESULTADOS E DISCUSSÃO}

\section{Cultivo do micro-organismo e obtenção da biomassa}

Para a obtenção dos polissacarídeos, os cultivos foram realizados de acordo com Dominato ${ }^{17}$ e as condições utilizadas foram as que apresentaram maior rendimento de biomassa. Para este trabalho foram realizados 6 cultivos do C. gloeosporioides rendendo 53 gramas de biomassa com cor acinzentada, como podem ser vistos na Figura 1SD.

\section{Extração dos polissacarídeos}

Os processos de extração dos polissacarídeos da biomassa seguiram procedimentos já descritos na literatura. ${ }^{18,20,21} \mathrm{~A}$ primeira extração efetuada com álcool etílico, removeu $16 \%$ de compostos hidrofóbicos e de pequena massa molecular, como oligossacarídeos livres, gerando um resíduo de 45 gramas, que após maceração foi submetido a extração aquosa a quente $(4 \mathrm{x})$, procedimento capaz de isolar polissacarídeos da parede celular como: $\beta$-glucanas, galactanas e mananas. ${ }^{12,18,22-24}$ Os extratos aquosos foram reunidos e congelados $\left(\mathrm{E}_{\mathrm{H} 2 \mathrm{O}-\mathrm{C}}\right)$. No descongelamento surgiu um precipitado, que se manteve insolúvel à temperatura ambiente. Dessa forma esse procedimento foi repetido até que nenhum precipitado se formasse no descongelamento; essa é uma técnica simples para separar polissacarídeos lineares dos ramificados. Segundo Ruthes, ${ }^{25}$ polissacarídeos lineares ou com porcentagens menores de ramificação são normalmente encontrados na fração insolúvel, enquanto os mais ramificados são encontrados na fração solúvel de um extrato aquoso.

A fração solúvel foi precipitada com álcool etílico na proporção de 1:3 e após diálise e liofilização pesou 2,23 g ( $\left.\mathrm{PE}_{\mathrm{H} 2 \mathrm{O}-\mathrm{C}}\right)$. As quantificações de açúcar total e proteínas para $\mathrm{PE}_{\mathrm{H} 2 \mathrm{O}-\mathrm{C}}$ resultaram em 94 e $6 \%$, respectivamente, e a hidrólise ácida mostrou que a fração é constituída de $41 \%$ de glucose, proporções semelhantes de galactose $(26 \%)$ e manose (25\%), além de um pequeno percentual de ramnose (8\%). A cromatografia de permeação em gel acoplada a um detector de índice refração (HPSEC/RID) apresentou 3 picos, indicando a presença de 3 ou mais polissacarídeos (Figura 2A) que se separaram, provavelmente, de acordo com a massa molecular. Essa análise é fundamental para indicar os caminhos futuros da investigação, uma vez que a caracterização química solicita um material homogêneo.

\section{Purificação dos polissacarídeos}

Considerando a diferença da massa molecular o procedimento escolhido para obter um material homogêneo foi a cromatografia 
de filtração em gel Sepharose CL-6B, a pressão normal. O perfil gráfico do experimento (Figura $2 \mathrm{~B}$ ) mostrou a presença de 5 picos, denominados $\mathrm{P}_{\mathrm{I}}$ a $\mathrm{P}_{\mathrm{v}}$. A análise de alíquotas de cada pico por HPSEC/RID (Figura 2C) sinalizou que apenas $\mathrm{P}_{\mathrm{IV}}$ e $\mathrm{P}_{\mathrm{V}}$ apresentaram comportamento de macromoléculas homogêneas e a ausência de proteínas pelo método de Bradford ${ }^{16}$ indicou que essas frações são constituídas unicamente de carboidratos.

Para conhecer a composição monossacarídica das frações consideradas puras alíquotas de $\mathrm{P}_{\mathrm{IV}}$ e $\mathrm{P}_{\mathrm{V}}$ foram separadas, hidrolisadas e analisadas por HPAEC/PAD e os resultados são mostrados na Tabela 1.

Dos polissacarídeos obtidos no extrato aquoso do C. gloeosporioides, $\mathrm{P}_{\mathrm{IV}}$ indica estar puro para experimentos de caracterização química bem como em quantidade suficiente para os testes de atividade biológica. A massa molar aparente da fração $\mathrm{P}_{\mathrm{IV}}$ foi estimada em $2,8 \times 10^{4} \mathrm{~g} \mathrm{~mol}^{-1}$, a partir da comparação com uma curva de calibração com padrões de dextrana. O valor do índice de polidispersividade (Mw/Mn) de 1,17 indica um polímero pouco polidisperso. A composição monossacarídica de $\mathrm{P}_{\mathrm{IV}}$ (Tabela 1) revela que $95 \%$ da molécula é composta por galactose e glucose, podendo a manose (5\%) fazer parte da estrutura polimérica ou ser o elo entre o polissacarídeo e as proteínas (ou glicoproteínas) presentes na parede celular. ${ }^{26}$

\section{Caracterização química do heteropolissacarídeo $\left(\mathbf{P}_{\mathrm{IV}}\right)$ por RMN}

Análises de ressonância magnética nuclear de ${ }^{1} \mathrm{H}$ e ${ }^{13} \mathrm{C}$ mono e bidimensionais foram realizadas para caracterizar a estrutura de $\mathrm{P}_{\mathrm{IV}}$. $\mathrm{O}$ espectro de ${ }^{1} \mathrm{H}$ (Figura $3 \mathrm{~A}$ ) mostrou três sinais anoméricos intensos em 5,39, 5,25 e 5,04 ppm. ${ }^{1} \mathrm{H}$ anoméricos com menor intensidade também foram observados. No espectro de $\mathrm{RMN}$ de ${ }^{13} \mathrm{C}$ (Figura 3B) foram encontrados três sinais mais intensos em 108,3, 107,4 e 99,8 ppm e outros menos intensos entre 103,0 a 98,7 ppm. De acordo com a literatura e os valores de deslocamentos químicos, os sinais em $\delta$ 108,3 e 107,4 ppm correspondem a unidades $\beta$-Dgalactofuranosídicas $1 \rightarrow 5$ e $1 \rightarrow 6$ substituídas, respectivamente, ${ }^{27} \mathrm{e}$ 99,8 ppm foi atribuído às unidades $\alpha$-D-glucopiranosídicas. ${ }^{21}$

De acordo com o espectro de RMN de ${ }^{13} \mathrm{C}$-DEPT (Figura 3C), as unidades $\beta$-D-galactofuranosídicas $1 \rightarrow 6$ substituídas apresentam um sinal intenso, invertido, em 69,8 ppm correspondendo ao C-6 envolvido
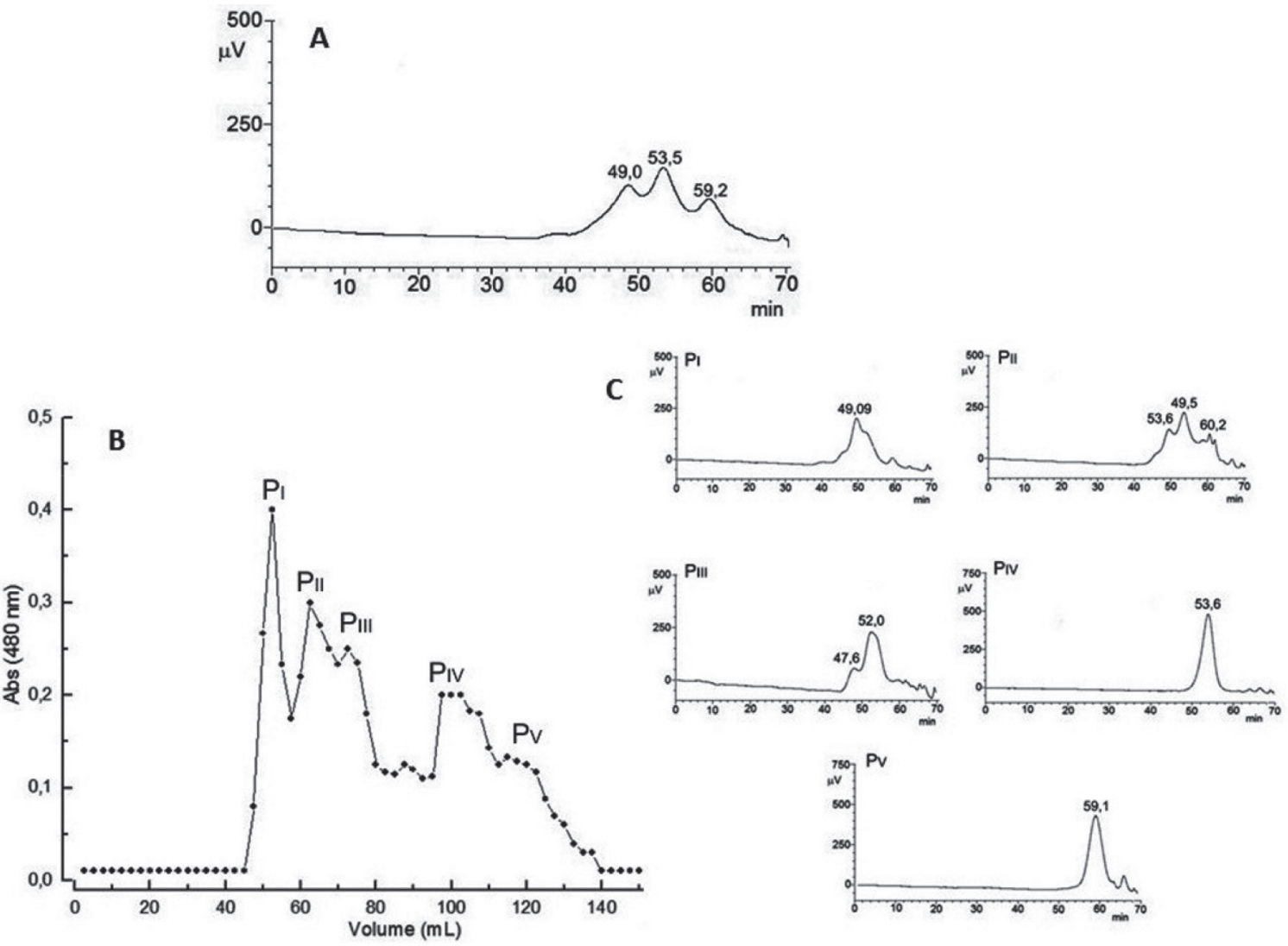

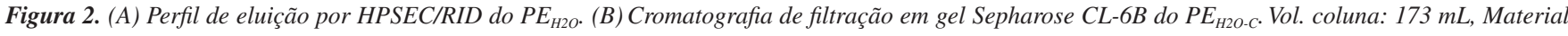
aplicado: $8 \mathrm{mg}$; Fluxo: 1,0 mL/min; Vol. fração: $2,5 \mathrm{~mL}$. (C) Perfil de eluição por HPSEC/RID das frações obtidas na coluna Sepharose CL-6B a partir do PE $E_{\text {H2O }}$

Tabela 1. Composição percentual relativa dos monossacarídeos após hidrólise ácida da fração solúvel do extrato aquoso ( $\mathrm{PE}_{\mathrm{H} 2 \mathrm{O}-\mathrm{c}}$ ) e das frações homogêneas $\left(\mathrm{P}_{\mathrm{IV}}\right.$ e $\mathrm{P}_{\mathrm{V}}$ ) provenientes da cromatografia de filtração em gel Sepharose CL-6B do fungo C. gloeosporioides

\begin{tabular}{|c|c|c|c|c|c|c|}
\hline \multirow[t]{2}{*}{ Frações } & \multicolumn{5}{|c|}{ Composição percentual relativa dos monossacarídeos } & \multirow{2}{*}{$\begin{array}{l}\text { Quantidade de } \\
\text { material (mg) }\end{array}$} \\
\hline & Fucose & Ramnose & Galactose & Glucose & Manose & \\
\hline $\mathrm{PE}_{\mathrm{H} 2 \mathrm{O}-\mathrm{C}}$ & $\operatorname{Traços}^{\mathrm{a}}$ & 8 & 26 & 41 & 25 & 2230,0 \\
\hline $\mathrm{P}_{\mathrm{IV}}$ & - & - & 61 & 34 & 5 & 140,0 \\
\hline $\mathrm{P}_{\mathrm{V}}$ & 2 & - & 56 & 30 & 12 & 53,0 \\
\hline
\end{tabular}

${ }^{\mathrm{a}}$ traços $<1 \%$. ${ }^{\mathrm{b}}$ valores determinados pelo método do fenol-ácido sulfúrico. ${ }^{15}$ 
na ligação glicosídica. As unidades $\beta$-D-galactofuranosídicas envolvidas em ligação $1 \rightarrow 5$ mostram o C-6 livre, também invertido, em $60,8 \mathrm{ppm}$. O outro sinal invertido no DEPT, referente ao carbono primário das unidades $\alpha$-D-glucopiranosídicas, C-6, pode ser visto em $61,5 \mathrm{ppm}$. Segundo a literatura muitos polissacarídeos da parede celular fúngica, solúveis em água, são constituídos por cadeias $\beta$-galactofuranosídicas de diferentes comprimentos e tipos de ligação, ${ }^{21,28}$ com ramificações de glucose.

A partir do espectro bidimensional heteronuclear HSQC (Figura 2S) foram correlacionados os ${ }^{1} \mathrm{H}$ anoméricos 5,04 e 5,25 ppm aos seus respectivos carbonos anoméricos 108,3 e 107,4 ppm das unidades $\beta$-D-galactofuranosídicas $1 \rightarrow 5$ e $1 \rightarrow 6$, substituídas e o sinal 5,39 ppm ao 99,8 ppm das unidades $\alpha$-D-glucopiranosídicas.

Do espectro bidimensional homonuclear COSY foi correlacionado o sinal de $\mathrm{H}-1$ (5,25 ppm) aos respectivos $\mathrm{H}-2$ (4,16 ppm) (Figura 3SA) e H-3 (3,71 ppm) (Figura 3SB) das unidades $\beta$-D-galactofuranosídicas ligadas em 6. Com essas atribuições, os deslocamentos químicos para C-2 (81,8 ppm) e C-3 (80,3 ppm), da mesma unidade, puderam ser obtidos no HSQC (Figura $2 \mathrm{~S}$ ). No estudo do espectro HMBC foi possível correlacionar o C-3 dessa unidade (80,3 ppm) ao H-1 da unidade glucopiranosídica $(5,39 \mathrm{ppm})$, sugerindo substituição em $O-3$ por $\alpha$-D-glucopiranose (Figura 3SC). Deve-se observar a ausência de um sinal próximo a $88 \mathrm{ppm}$, característico de unidades galactofuranosídicas 2-O substituídas, indicando que esse tipo de substituição, comum em polissacarídeos e oligossacarídeos de parede celular de fungos, inexiste nessa estrutura. ${ }^{21,28}$

Também no espectro HMBC (Figura 3SC) são visualizados correlação entre o C-6 (69,8 ppm) da unidade $\beta$-D-galactofuranosídica 6- $O$ ligado ao $\mathrm{H}-1(5,04 \mathrm{ppm})$ da unidade $\beta$-D-galactofuranosídica 5- $O$ ligada, indicando as sequências abaixo (I e II) como fazendo parte da estrutura do heteropolissacarídeo.

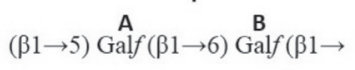

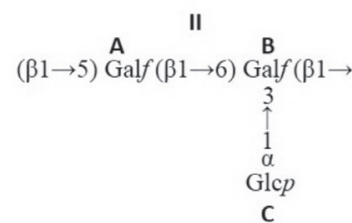

\section{Avaliação da citotoxicidade}

Estudos do potencial citotóxico in vitro de extratos de fermentação, ${ }^{29}$ de extratos de micélio ${ }^{30}$ e de metabólitos liberados no meio de cultivo por fungos do gênero Colletotrichum ${ }^{31,32}$ são encontrados na literatura científica, porém o potencial citotóxico de polissacarídeos extraídos da biomassa Colletotrichum gloeosporioides, em linhagens celulares, ainda não foi relatado. Dessa forma, este é o primeiro estudo que avalia a citotoxicidade in vitro de um polissacarídeo extraído da biomassa deste micro-organismo.

Nesse estudo, os resultados obtidos pelo ensaio do MTT indicam que a viabilidade das células $\mathrm{CHO}-\mathrm{K} 1$, expostas às diferentes concentrações do heteropolissacarídeo, não apresentaram diferenças significativas quando comparadas com a viabilidade do controle negativo (CN), nos tempos experimentais de 24 e 48 h (Figura 4). Kim e colaboradores ${ }^{33}$ avaliaram a citotoxicidade de endopolissacarídeos extraído do micélio do fungo Inonotus obliquus e observaram que a maioria das células tumorais e das células normais testadas não tiveram a sua viabilidade celular afetada, mesmo quando expostas a altas concentrações do polissacarídeo. Galinari e colaboradores ${ }^{34}$ mostraram que frações de polissarídeos extraídos de parede celular da levedura Kluyveromyces marxianus CCT773 inibiram a proliferação da célula tumoral Hep-G2, mas não foram citotóxicas para células tumorais HeLa e apresentaram pouca citotoxicidade para a linhagem celular normal 3T3.
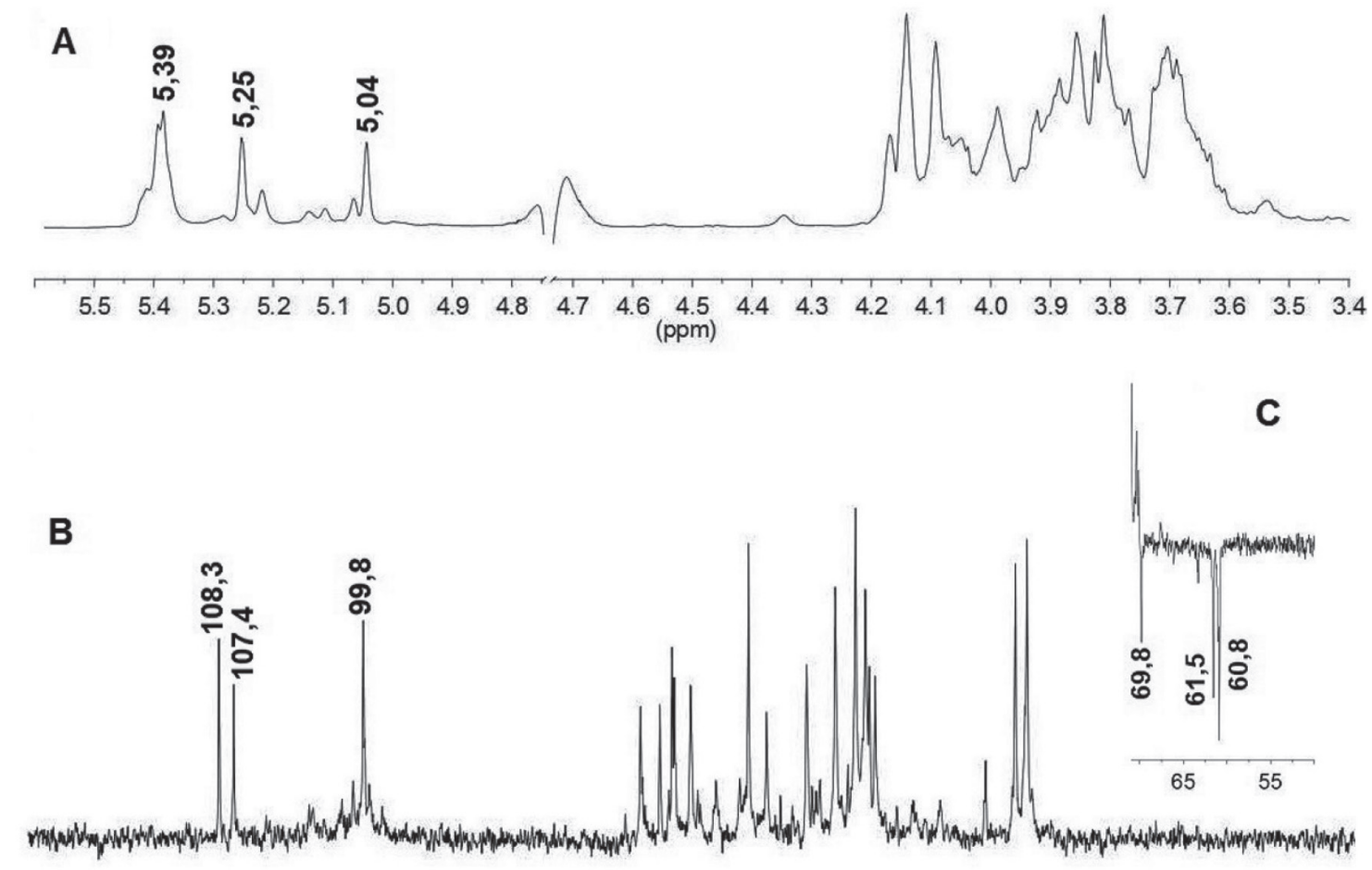

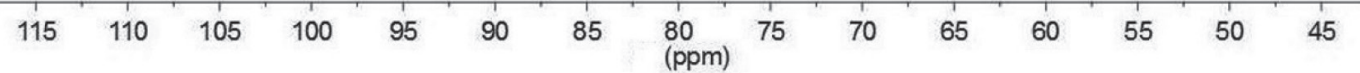

Figura 3. Espectros de $R M N$ de ${ }^{1} \mathrm{H}(\mathrm{A}), \mathrm{RMN}$ de ${ }^{13} \mathrm{C}(\mathrm{B})$ e região do $R M N{ }^{13} \mathrm{C}-\mathrm{DEPT}(\mathrm{C})$ do heteropolissacarídeo $\left(P_{I V)}\right.$ obtido por cromatografia de filtração em gel Sepharose CL-6B do extrato aquoso do C. gloeosporioides 


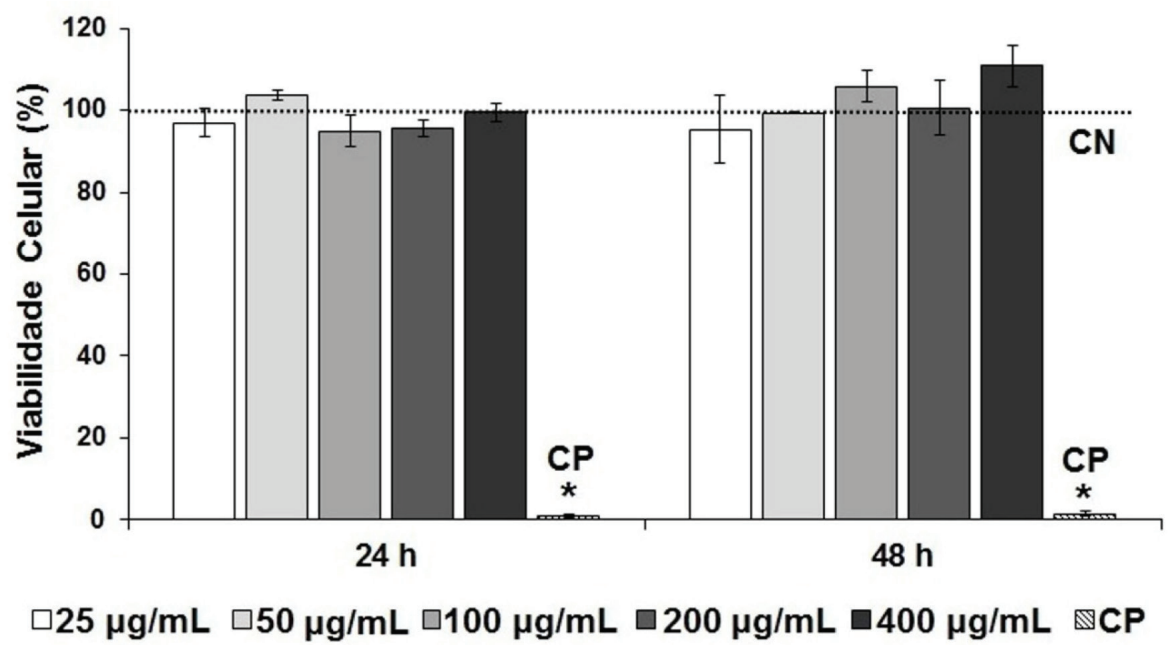

Figura 4. Viabilidade celular (\%) das linhagens $\mathrm{CHO}-\mathrm{K} 1$ expostas a diferentes concentrações do polissacarídeo $P_{I b}$ somente ao meio de cultura (CN- linha tracejada) ou ao Triton-X $(C P)$ por 24 e 48 horas. As linhas horizontais representam as médias e as linhas verticais o desvio padrão. * indica diferença significativa comparado com $C N$, que foi considerado $100 \%(P<0.05)$

A ausência de citotoxicidade apresentada pelo heteropolissacarídeo do C. gloeosporioides nas células CHO-K1, que é uma linhagem normal, pode ser interpretada como positiva, abrindo novas perspectivas para futuros estudos toxicológicos tanto em outras linhagens celulares normais, quanto em células cancerosas, avaliando seu potencial como agente antitumoral. A ausência de citotoxicidade dos compostos em células normais é uma característica fundamental, mas difícil de ser encontrada. Isso tem se tornado um grande desafio para a medicina na busca por novos fármacos antitumorais.

\section{CONCLUSÃO}

Condições de cultivo pré-estabelecidas permitiram o crescimento do fungo ascomiceto Colletotrichum gloeosporioides favorecendo a produção de biomassa que, após procedimentos extrativos, resultou em uma fração rica em polissacarídeos. Técnicas de purificação por congelamento/descongelamento e cromatografia de filtração em gel Sepharose CL-6B permitiram o isolamento da fração $\mathrm{P}_{\mathrm{IV}}$, considerada homogênea por HPSEC/RID, com massa molar de $2,8 \times 10^{4} \mathrm{~g} \mathrm{~mol}^{-1}$, $\mathrm{Mw} / \mathrm{Mn} 1,17$, e $100 \%$ de açúcar total com galactose (61\%), glucose (34\%) e manose (5\%) como seus constituintes monossacarídicos. Análises de ressonância magnética nuclear de ${ }^{1} \mathrm{H} \mathrm{e}{ }^{13} \mathrm{C}$, mono e bidimensionais, forneceram espectros que permitem concluir que $\mathrm{P}_{\mathrm{IV}}$ é um heteropolissacarídeo com a cadeia principal formada por unidades $\beta$-D-galactofuranosídicas com ligações $1 \rightarrow 5$ e ligações $1 \rightarrow 6$, sendo algumas dessa última unidade substituída em $O-3$ por resíduos $\alpha$-D-glucopiranosídicos. Ensaios de citotoxicidade (MTT) indicaram que a viabilidade das células CHO-K1, expostas às diferentes concentrações do heteropolissacarídeo, não apresentaram diferenças significativas quando comparadas com a viabilidade do controle negativo $(\mathrm{CN})$, nos tempos experimentais de 24 e $48 \mathrm{~h}$. Essa resposta sinaliza a possibilidade da continuidade dos testes de citotoxicidade tanto em outras linhagens de células normais como em células tumorais.

\section{MATERIAL SUPLEMENTAR}

Estão disponíveis em http://quimicanova.sbq.org.br, na forma de arquivo PDF, com acesso livre, fotos do cultivo do fungo Colletotrichum gloeosporioides e de sua biomassa (Figura 1S), espectro de RMN bidimensional HSQC (Figura 2S) e das regiões selecionadas dos espectros de RMN bidimensional homonuclear (COSY) (Figuras 3SA e 3SB) e heteronuclear (HMBC) do heteropolissacarídeo $\mathrm{P}_{\mathrm{IV}}$ (Figura 3SC).

\section{AGRADECIMENTOS}

À CAPES pela bolsa de estudo da doutoranda S. M. A. Alexandre.

\section{REFERÊNCIAS}

1. Cui, S. W. Em Structural Analysis of Polysaccharides; Cui, S. W., ed.; Taylor \& Francis Group: Boca Raton, 2005, cap. 3.

2. Orlandelli, R. C.; Vasconcelos, A. F. D.; Azevedo, J. L.; Corradi da Silva, M. L.; Pamphile, J. A.; Biochimie Open 2016, 2, 33.

3. Ferracini-Santos, L.; Sato, H. H.; Quim. Nova 2009, 32, 322.

4. Zen, C. K.; Silva, K. P.; Bertolin, T. E.; Reinehr, C. O.; Colla, L. M.; Revista de Ciências Exatas Aplicadas e Tecnológicas 2014, 6, 40.

5. Giavasis, I.; Curr. Opin. Biotechnol. 2014, 26, 162.

6. Oliveira, N. F.; Santos, G. R. C.; Xisto, M. I. D. S.; Santos, G. M. P.; Nucci, M.; Haido, R. M. T.; Barreto-Bergter, E.; Med. Mycol. 2018, O, 1.

7. El-Enshasy, H. A. Em Filamentous Fungal Cultures- Process Characteristics, Products, and Applications; Yang, S. T., ed.; Elsevier: Amsterdam, 2007, cap. 9.

8. Souza, H. Q; Oliveira, L. A.; Andrade, J. S.; Ciênc. Tecnol. Aliment. 2008, 28, 116.

9. Zhao, C.; Gao, L.; Wang, C.; Liu, B.; Jin, Y.; Xing, Z.; Carbohydr. Polym. 2016, 144, 382.

10. Smiderle F.; Alquini, G.; Tadra-Sfeir, M. Z.; Iacomini, M.; Wichers, H. J.; Van Griensven, L. J. D.; Carbohydr. Polym. 2013, 94, 91.

11. Jiang, J.; Kong, F.; Li, N.; Zhang, D.; Yan, C.; Lv, H.; Carbohydr. Polym. 2016, 147, 365.

12. Ruthes, A. C.; Carbonero, E. R.; Córdova, M. M.; Baggio, C. H.; Sassaki, G. L.; Gorin, P. A. J.; Santos, A. R. S.; Iacomini, M.; Carbohydr. Polym. 2013, 98, 761.

13. Menezes, M.; Anais da Academia Pernambucana de Ciência Agronômica 2006, 3, 170.

14. Park, S. H.; Choi, C. W.; Shim, M. Y.; Park, W. M.; Hwang, S. S.; Koo, J. M.; Biotechnol. Lett. 2001, 23, 1719.

15. Dubois, M.; Gilles, K. A.; Hamilton, J. K.; Rebers, P. A.; Smith, F.; Anal. Chem. 1956, 28, 350 .

16. Bradford, M. M.; Anal. Biochem. 1976, 72, 248. 
17. Dominato, A. A. G.; Tese de Doutorado, Universidade Estadual Paulista, Brasil, 2017.

18. Alexandre, S. M. A.; Corradi da Silva, M. L.; Vasconcelos, A. F. D.; Exposti, D. T. D.; Tischer, C. A.; Prieto, A.; Diaz, D.; Kaneno, R.; Int. J. Biol. Macromol. 2018, 115, 106.

19. Mosmann, T. J. Immunol. Methods 1983, 65, 55.

20. Ge, Q.; Zhang, A. Q.; Sun, P. L.; Food Chem. 2009, 114, 391.

21. Corradi da Silva, M L.; Exposti, D. T. D.; Vasconcelos, A. F. D.; Alexandre, S. M. A.; Silveira, J. L. M.; Ducatti, D. R. B.; Carbohydr. Polym. 2013, 98, 1353.

22. Han, X. Q.; Wu, X. M.; Chai, X. Y.; Chen, D.; Dai, H.; Dong, H. L.; Ma, Z. Z.; Gao, X. M.; Tu, P. F.; Food Res. Int. 2011, 44, 489.

23. Smiderle, F. R.; Olsen, L. M.; Carbonero, E. R.; Baggio, C. H.; Freitas, C. S.; Marcon, R.; Santos, A. R. S.; Gorin, P. A. J.; Iacomini, M.; Eur. J. Pharmacol. 2008, 597, 86.

24. Zhou, S.; Liu, Y.; Yang, Y.; Jia, W.; Tang, Q.; Tang, C.; Feng, N.; Zhang, J.; Bioact. Carbohydr. Diet. Fibre 2013, 1, 99.

25. Ruthes, A. C.; Smiderle, F. R.; Iacomini, M.; Carbohydr. Polym. 2015, 117, 753.
26. Latgé, J.P.; Beauvais, A.; Curr. Opin. Microbiol. 2014, 20, 111.

27. Cordeiro, L. M. C.; Beilke, F.; Bettim, F. L.; Reinhardt, V. F.; Rattmann, Y. D.; Iacomini, M.; Carbohydr. Polym. 2012, 90, 1779.

28. Ahrazem, O.; Prieto, A.; Leal, J.A.; Gómez-Miranda, B.; Domenech, J.; Jiménez-Barbero, J.; Bernabé, M.; Carbohydr. Res. 1997, 303, 67.

29. Packiaraj, R.; Jeyakumar, S.; Ayyappan, N.; Adhirajan, N.; Premkumar, G.; Rajarathinam, K.; Muthuramkumar, S.; Studies in Fungi 2016, 1, 104.

30. Palem, P. P. C.; Kuriakose, G. C.; Jayabaskaran, C.; PloS One 2015, 10, e0144476.

31. Gangadevi, V.; Muthumary, J.; Afr. J. Biotechnol. 2007, 6, 1382.

32. Yang, Z. J.; Yang, T.; Luo, M. Y.; Xia, X.; Chen, D. J.; Qian, X. P.; Acta Pharm. Sin. B 2013, 48, 891.

33. Kim, Y. O.; Park, H. W.; Kim, J. H.; Lee, J. Y.; Moon, S. H.; Shin, C. S.; Life Sci. 2006, 79, 72

34. Galinari, E.; Almeira-Lima, J.; Macedo, G. R.; Mantovani, H. C.; Rocha, H. A. O.; Int. J. Biol. Macromol. 2018, 109, 837. 